Pacific's goal is eradication by 1995 . It has six countries with endemic polio and has developed national eradication programmes and instituted training. Other regions are not so far advanced. ${ }^{6}$ Essentially two barriers need overcoming. These are technical and politico-financial. Technical difficulties relate to producing heat stable vaccine in large enough quantities and getting it into the field. Once there, the problem is achieving good seroconversion among tropical populations after oral polio vaccine. ${ }^{7}$ This has been highlighted by outbreaks of disease in some well vaccinated populations, which seem due to vaccinated children not being immunised and the build up of a susceptible population to the level at which an epidemic occurs. ${ }^{89}$ The research component of the eradication programme is addressing these problems, through examining different formulations of oral polio vaccine and changing the regimens (even combining injectable and oral vaccines).

More intractable are the political and financial problems. It has proved more difficult than it was with smallpox to obtain high priority for funding polio's eradication. Some donors are unconvinced that this is an appropriate target for the expanded programme on immunisation. Others doubt whether the strategies are transferrable from the relatively sophisticated, highly urbanised Americas to less developed rural countries. A major review of the strategy is now underway. Being carefully considered is the use of injectable vaccine to overcome the problems of poor seroconversion to oral vaccine, which occurs especially to types 1 and 3 in tropical countries.

For Europe the problem is different. Bulgaria, Romania, Turkey, and the states of the former Soviet Union still have an appreciable incidence of poliomyelitis. Although not the case for the rest of Europe, there clearly needs to be some mechanism in place for containing the inevitable importations, which will continue until the virus is eradicated.

Countries' main concern, however, is to prove that they have already eradicated indigenous transmission. Surveillance of the type described by Joce and colleagues ${ }^{1}$ is necessary to identify vaccine associated and imported cases. In addition, efforts must be made to show that no wild polio virus is circulating, which is a daunting task. The high levels of vaccination ensure that sewage is replete with polio viruses, which should be analysed to distinguish whether they are wild or vaccine strains. The mutation of vaccine strains adds to this difficulty. What does a negative sample tell you statistically in terms of number of potential excretors in the sewer's catchment? These are some of the problems which scientists are now grappling with.

The clock is ticking. WHO need to persuade politicians and those in charge of health services nationally that the eradication of polio is a sensible and realistic target for them in the face of many competing demands. They must persuade the donor agencies of the same. Finally, WHO must solve various technical difficulties to ensure success in places such as subSaharan Africa. The science will be the least of these challenges.

ANDREW J HALL

Senior Lecturer in Epidemiology

Epidemiology and Population Sciences Department,

London School of Hygiene and Tropical Medicine,

London WC1E 7HT

1 Joce R, Wood D, Brown D, Begg N. Paralytic poliomyelitis in England and Wales, 1985-91. BMJ 1992;305:79-82

2 Wright PF, Kim-Farley RJ, de Quadros CA, Robertson SE, McNair Scott R, Ward NA, et al. Strategies for the global eradication of poliomyelitis by the year 2000. N Engl f Med 1991;325:1774-9.

3 Expanded Programme on Immunization. Manual for immunization programme managers on activities related to polio eradication. Geneva: World Health Organisation, 1989. (WHO/EPI/POLIO/89.1.)

Expanded Programme on Immunization. Manual for the virological investigation of poliomyelitis, Geneva: World Health Organisation, 1990. (WHO/EPI/CDS/POLIO/90 1)

Rico-Hesse R, Pallansch MA, Nottay BK, Kew OM. Geographic distribution of wild poliovirus typ 1 genotypes. Virology 1987;160:311-22.

Expanded Programme on Immunization. Programme report for the biennium 1990-1991. Geneva: Expanded Programme on Immunization. Programme report for
World Health Organisation, 1992. (WHO/EPI/DON/92.1.)

7 Patriarca PA, Wright PF, John TJ. Factors affecting the immunogenicity of oral poliovirus vaccine Patriarca PA, Wright PF, John TJ. Factors affecting the immuno

8 Sutter RW, Patriarca PA, Brogan S, Malankar PG, Pallansch MA, Kew OM, et al. Outbreak of Sutter RW, Patriarca PA, Brogan S, Malankar PG, Pallansch MA, Kew OM, et al. Outbreak of
paralytic poliomyelitis in Oman: evidence of widespread transmission among fully vaccinated paralytic poliomyelitis in Oman: $\mathrm{e}$
children. Lancet 1991;338:715-20.

9 Otton MW, Deming MS, Jaiteh KO, Flagg EW, Forgie I, Sanyang Y, et al. Epidemic poliomyelitis in the Gambia following the control of poliomyelitis as an endemic disease. 1. Descriptive findings Am f Epidemiol 1992;135:381-92.

\title{
Promoting sexual health
}

\section{The best way to tackle HIV}

The struggle against HIV needs reinvigorating. A vaccine and a cure are as far away as ever, and the main thrust of a strategy on HIV must be to encourage people to behave in a way that will reduce or eliminate their chances of becoming infected. Unfortunately, it is difficult to sustain such a campaign. Consequently homosexual men are beginning to be less careful about practising safe sex, and heterosexuals have simply not adopted safe sex in large enough numbers to prevent HIV spreading through the heterosexual population.

It was these anxieties that led to a group being assembled at Leeds Castle in Kent last week to discuss how to revitalise the campaign against HIV infection. Members of the group came from the health and education services, health promotion, the mass media, and advertising, and the results of the meeting are being transmitted to ministers. One conclusion was that sexual health should be included as one of the priorities in the government's health strategy, and, as I write, it seems that this will be the case. The meeting was thus given energy not only by the urgency, seriousness, and scale of the problem but also by the probability that the government would commit itself to action.
The meeting began by hearing research papers on the difficulties of changing people's behaviour. A large body of research shows that it can be done but offers no universal model on how. Knowledge and attitudes are more easily changed than behaviour, but changing knowledge and attitudes is neither a sufficient nor even a necessary condition for changing behaviour. The difficulty of changing behaviour is related to the clarity and specificity of the health message being delivered, the ease with which change can be made, and the degree of perceived threat. "Go for breast screening" is clear and more easily acted on than "Be more responsible for your own health." The problem with changing people's behaviour to reduce their chance of being infected with HIV is that the message is unclear (to those issuing and receiving it), the change required is large, and the threat is perceived by heterosexuals as small. Furthermore, most people do not think of sexual behaviour in health terms. Another profound problem with transmitting messages on sexual behaviour is that most people in Britain have great difficulty in talking about sexuality; a corollary is that the language used is often seen as either too technical or too explicit. These are some of 
the reasons why the mass media have had only limited success in relation to HIV and sexual behaviour. Generally they can raise awareness and increase knowledge of HIV but are ineffective at changing behaviour.

Confronted with this analysis of the difficulties of changing sexual behaviour, the people at Leeds Castle thought that the first priority was to be clear about the message. "Use a condom" has the advantage of being clear and simple, but most people thought that a more positive and upbeat message was required. Britain needs a society in which people feel able to talk about sexuality and exercise choice in sexual relationships. Roughly half of 16 year olds in Britain have had sexual intercourse, yet most (girls in particular) experience regret immediately after their first sexual experience. A society in which young people can talk more easily about sexuality - to their partners, friends, parents, teachers, and doctors-should be a society in which fewer people have unprotected - and unfulfilling - sexual intercourse so young. The Dutch, for instance, are much less inhibited in dealing with sexual matters yet have a much lower teenage pregnancy rate than Britain.

There was general dissatisfaction at Leeds Castle with the phrase "safer sex": it is dull and restrictive and doesn't get through. We need a phrase that denotes a more erotic, positive, and diverse kind of sexual behaviour that covers much more than simply penetrative sex. "Better sex," "green sex," and "real sex" were all considered, but none seemed right. More work needs to be done to get the message clear and correct.

If the aim is to be much more open and positive about sexual behaviour then there will have to be considerable political and social change in Britain. If the government does make sexual behaviour a priority in its health strategy then that will be an important step, but many government departments - particularly the Department of Education- will need to change their attitudes. Any government that seems to be promoting rather than restricting sexual debate is likely to come under attack from moralists, but the group at Leeds Castle thought that the government - and the mediahave a duty not to bend to these people. Thus, although some people object strongly to sex education in primary schools, the vast majority of parents want it; and while some are offended by advertisements for tampons and contraceptives, most people are not.

Although several of those at the meeting worked for the mass media, most thought that resources should be diverted from mass media advertising to campaigns through schools, health centres, community groups, employers, and unions. The mass media will undoubtedly become involved with any campaign to promote sexual health, and some of the messages transmitted by them will be clear and positive-although many will be reactionary and obfuscatory. The problems with trying to use schools, health centres, and other existing systems to promote sexual health are that many of them (for example, schools and HIV district coordinators) are in disarray and many of those who work in them feel uneasy talking about sexuality. Considerable training will be needed.

The difficulty that the group at Leeds Castle had with defining the issues and beginning to address them illustrates how difficult the problems are. To attempt to change a nation's attitude to sexuality and risky sexual behaviour is an enormous task. It may even seem impossible until we remember that government ministers until very recently found it difficult to talk about condoms; now we have a secretary of state for health who can talk about anal intercourse without embarrassment. Deep cultural attitudes can be changed.

Editor,

RICHARD SMITH

\section{Service increment for teaching and research}

\section{Still problems concerning definition and use}

The service increment for teaching and research (SIFTR) amounts to $£ 30492$ per medical student per year (at 1989-90 prices) and may provide up to a quarter of a large teaching hospital's income. It is therefore hardly surprising that controversies exist concerning how the increment is calculated, the purposes for which it should be used, and how it should be allocated.

The concept of a service increment for teaching was developed by the Resource Allocation Working Party as part of a formula for financial allocations to the regional authorities in $1976 .{ }^{1}$ It was intended to cover the additional costs to the NHS of providing facilities for clinical teaching for medical and dental students and was based on the difference between the average costs of teaching and non-teaching acute hospitals. The actual sum allocated for the increment was only three quarters of this difference-because it was estimated that this proportion of the additional costs per case in a teaching hospital was attributable to the teaching of undergraduate students.

The Resource Allocation Working Party's review in 1986 extended the increment to take account of additional costs, such as research and case mix. ${ }^{2}$ This review acknowledged that a teaching hospital incurs expenditure through maintaining a critical mass of people, equipment, patient activity, and skill, which is necessary for the hospital to fulfil its undergraduate and postgraduate teaching activities, deal with complicated cases, and conduct research. The working party concluded that there was "a strong case in principle, therefore, for basing financial protection for the additional cost per case of teaching hospitals, on all those elements of teaching hospital costs resulting from academic activity which go beyond what a region would otherwise have planned for its population."

The working party compared the costs of 60 teaching hospitals (identified with the help of medical school deans) with those of another 198 acute hospitals. On the basis of an analysis of the relative importance of the different costs of teaching hospitals the working party suggested that between $95 \%$ and $100 \%$ of the excess costs could be attributed to teaching and research. It recommended, therefore, that the allocation for teaching should be increased from $75 \%$ to $100 \%$ of the median excess costs per student, thus incorporating at least in theory the costs incurred through research activity. SIFTR was born.

The theoretical $25 \%$ increase in the allocation became an actual increase of only $2 \%$ in the annual amount attracted by each medical student. This apparently was due to the narrowing of the gap between the cost per case in teaching 